\title{
The importance of COVID-19 testing to assess socioeconomic fatality drivers and true case fatality rate. Facing the pandemic or walking in the dark?
}

Cristina Isabel Ibarra-Armenta ( $\sim$ cibarra@uas.edu.mx)

Universidad Autonoma de Sinaloa https://orcid.org/0000-0002-3863-0206

Moises Alejandro Alarcon-Osuna

Universidad de Guadalajara

\section{Research}

Keywords: COVID-19 testing, Case Fatality Rate, Health infrastructure, OCDE, Stringency index

Posted Date: October 21st, 2020

DOI: https://doi.org/10.21203/rs.3.rs-30743/v2

License: (c) (i) This work is licensed under a Creative Commons Attribution 4.0 International License.

Read Full License 


\section{The importance of COVID-19 testing to assess socioeconomic fatality drivers and 3 true case fatality rate.}

4 Facing the pandemic or walking in the dark?

5

Ibarra-Armenta, Cristina Isabel ${ }^{1}$ Economics and Social Sciences Faculty, Universidad Autonoma de Sinaloa, Blvd. Universitarios y Av. de las Américas, Unidad 3 s/n, Ciudad Universitaria. CP. 80010 Culiacán, Sinaloa. México. E-mail: cibarra@uas.edu.mx

Alarcon-Osuna, Moises Alejandro. Universidad De Guadalajara. E-mail: moises.alarcon@cucea.udg.mx

\section{Abstract}

To date, Europe and other developed countries have become the centre of the pandemic. While the COVID-19 spread to developing countries and less developed regions seems to be still very low. The case fatality rate (CFR) differs greatly among countries, and genetics, health systems, population characteristics as well as public health and social measures (lockdown measures) are believed to be the determinants of such diversity. Through an Ordinal Probit, Cross Section and Panel data models for 71 countries, it is shown that the nations applying more tests per million inhabitants are also those reporting more cases and deaths, yet greater testing helped to reduce CFR, while health infrastructure and population health indicators could not be confirmed as drivers for CFR. The Stringency Index showed a negative correlation with the number of deaths. Our main finding is that the pandemic concentration in developed nations is highly related to their ability and resources for tracking the pandemic. Three additional conclusions are drawn: first, the true CFR and its drivers at national levels cannot be estimated without increasing the number of tests per million inhabitants; second, there is an under-identification of cases and/or deaths, and the countries applying more tests are most clearly identifying the reality of the pandemic, while countries with fewer cases are actually still walking in the dark; third lockdown measures have been effective at reducing the number of deaths.

\section{Key words: COVID-19 testing, Case Fatality Rate, Health infrastructure, OCDE, Stringency}

index

\footnotetext{
${ }^{1}$ Corresponding author. Cibarra@uas.edu.mx
} 
33 The COVID-19 outbreak has disrupted economic and social life all over the world, and its

34 scope is not yet certain, but it is definitively deep and lasting. Governments, policymakers,

35 politicians, physicians, medical employees, scientifics and international organisations have

36 gathered together into a virtual space for collaboration to find answers to all the raised

37 questions. Apart from defeating the virus by developing a vaccine and/or finding a drug

38 largely effective for patients with COVID-19, among the most important governments

39 concerned in the short term, the impact of COVID-19 on the health system, namely,

40 availability of health infrastructure, as well as finding the best strategy for reducing as much

41 as possible the effects of the pandemic in economic and social aspects. The World Health

42 Organization (WHO) has recommended social distancing measures to slow down virus

43 spreading and, in this way, prevent medical services from collapse. However, in the long

44 term, the WHO expects that the virus will remain present with periods of low-level infections,

45 perhaps with seasonal increments (WHO,2020). Therefore, governmental strategies should

46 aim to ensure that health services are available to attend COVID-19 patients without

47 compromising all the other health services in the medium and long terms. In the document

48 published on $15^{\text {th }}$ April by the WHO (2020), a set of recommended actions for public policies

49 are outlined, in which the continuous tracking of the virus is recommended to be able take

50 regional public health and social measures, so-called lockdowns, only at high-risk regions, or

51 places where contagions return high. At the centre of the recommendations is the importance

52 of testing (Sanchez, 2020) and the use of serological tests in line with scientific

53 recommendations (CDC, 2020). Likewise, the Organisation for Economic Cooperation and

54 Development (OECD) (2020) highlights the importance of testing by presenting an analysis 
55 of a better performance observed in countries with a high number of tests per million 56 inhabitants. It is also pointed out that the increase in tests will help gather essential 57 information to study the virus, especially to determine whether the population is developing 58 antibodies, whether the virus can mutate and how to deal with COVID-19 in the following months. In addition, it is particularly important to find the asymptomatic proportion in the

60 population, first to assess the probability of contagion from such individuals to others and 61 second, to estimate the true CFR.

62 There is great diversity in the public health and social measures taken by each country against 63 the pandemic, which can be grouped into three lines of action. First, it ensures a good supply 64 of medical equipment and vacates the hospitals as much as possible. Second, social 65 distancing measures, from banning international travel, suspending schools, encouraging 66 teleworking, etc. Third, economic measures are needed to guarantee the wellbeing of the 67 population, with special support for firms and families. Naturally, not all countries have 68 followed the same set of actions. In fact, there are wide differences in the economic and social 69 distance measures. Some countries implemented severe restrictions once the domestic 70 contagions increased considerably, such as Italy, France, and the United Kingdom, while 71 Peru and the United States (US) closed the international airports shortly after the first 72 COVID-19 case was confirmed, yet this measure was not that effective, especially for the 73 latter. Others implemented massive testing preventing the cases from exponential increase, 74 such as Iceland, Singapore and Korea (OECD, 2020). Additionally, among the countries with 
75 a larger number of applied tests is Luxemburg, which has recently been published to test all 76 its population ${ }^{2}$.

77 In addition, law enforcement capacity and political organisation might have also played a 78 significant role in this regard. For instance, in Mexico and the US, sub-national governments 79 could regulate regional social distance measures. Meanwhile, the economic organisation, 80 informality and the limited or null presence of the welfare state hinder the social and 81 economic lockdown (Loayza, 2020), namely, entrepreneurs and employees in the informal 82 economy might not access economic aid ${ }^{3}$. According to the World Labour Organization 83 (WLO), more than $60 \%$ of employment in the world is informal, breaking into regions; in 84 Africa, $85.8 \%$ of employment is informal, in Asia and the Pacific 68.2\%, 68.6\% in the Arab 85 States, $40.0 \%$ in the Americas and $25.1 \%$ in Europe and Central Asia ${ }^{4}$. In addition, according to Loayza (2020), in developing countries, lockdown measures are less effective for several

87 reasons, namely, people will continue to work if their income is compromised, confinement 88 in overcrowded dwellings with poor sanity access might increase the risk of contagion, and 89 displacement of people from urban to rural areas would move the contagions spreads to rural 90 areas, which frequently have less access to medical services and sanity.

91 It is important to note that there are 70 countries in the sample, and they concentrate $96 \%$ of 92 confirmed cases worldwide. The distribution is shown in Figure 1. It is clear that the 93 majority of cases are concentrated in developed countries, while developing economies

\footnotetext{
${ }^{2}$ Accessed $17^{\text {th }}$ May: https://www.forbes.com/sites/joshuacohen/2020/05/13/as-a-tiny-nation-tests-allinhabitants-for-coronavirus-the-world-awaits-the-results/?fbclid=IwAR3CnpQxnW9sG- o0gYUyCAqZw 3EglvZ4LafmSYtlb7mFz3YdRyg-AFRM\#7068808a2378

${ }^{3}$ Accessed $13^{\text {th }}$ May 2020 at: https://blogs.worldbank.org/voices/scaling-covid-19-crisis-response-now-willavoid-higher-costs-later

${ }^{4}$ Accessed $13^{\text {th }}$ May 2020: https://www.ilo.org/global/about-the-ilo/newsroom/news/WCMS 627189/lang-en/index.htm
} 
94 only account for approximately $20 \%$ of the cases. Africa registered only $1 \%$ of worldwide 95 cases.

Figure 1 Proportion of cases by country by $7^{\text {th }}$ May 2020. Source: own elaboration with data from Ourworldindata.org

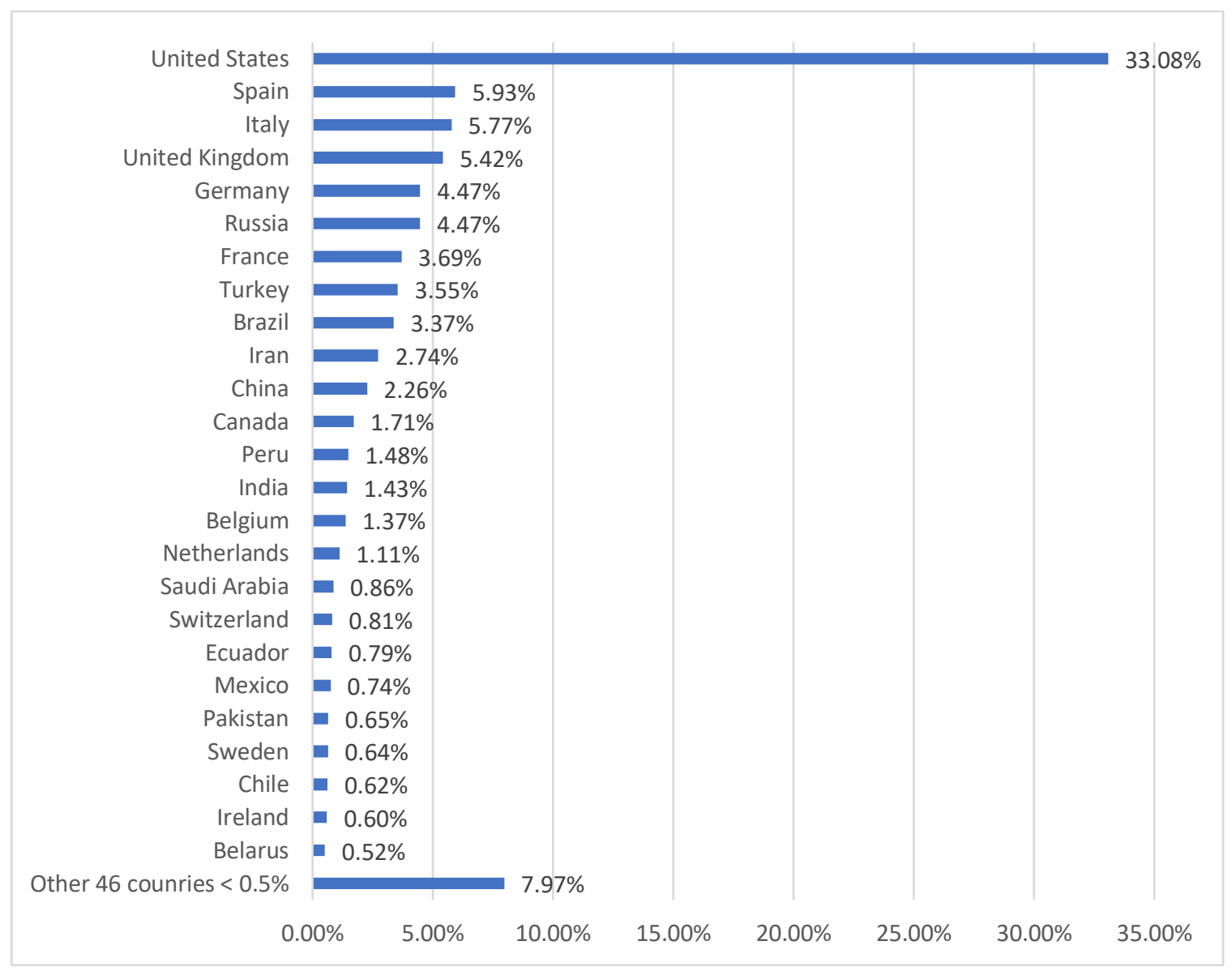

99 From the initial analysis presented with the Chinese experience, it has been stated that the health of individuals, as well as their age, are important drivers for virus fatalities (The Novel,

101 2020). However, there is still little evidence about the correlation between the aggregated 102 indicators of population health and health infrastructure and fatalities.

103 Resuming, the effectiveness of lockdown measures has been questioned, given that it is likely 104 that the virus will continue to spread in the long term, while there are huge economic losses. 105 The likely underidentification of cases in developing nations would prevent further control 
106 of the virus in the long term. Additionally, public responses might be more effective, as better

107 knowledge of driving socioeconomic determinants is found, for which further data need to

108 be generated. Consequently, this paper attempts to fill a gap in the literature by assessing

109 whether COVID-19 testing, lockdown measures, and socioeconomic country characteristics

110 are strong drivers of CFR, cases and deaths worldwide.

111 The paper is organised as follows: in the second section, the materials and methods are

112 explained, the third section presents the results, the fourth section presents a discussion, and

113 the fifth section summarises the conclusions and policy implications.

\section{Methods}

115 Data

116 The data employed were taken from different sources. For COVID-19 cases and testing, the 117 data came from ourwoldindata.org, in combination with GitHub ${ }^{5}$, and the data on cases, 118 deaths and tests ${ }^{\text {encompassed } 7}$ May. For health indicators, the $\mathrm{OECD}^{6}$ and $\mathrm{WHO}^{7}$ databases were 119 consulted. The data collected correspond to the most recent data available.

120 For the cross-section models, the countries included are those that reported a 3-day average 121 of 3 new deaths in at least one day. This criterion has been made to take out of the sample 122 the countries in which COVID-19 has not been widely spread until now. Upon this criterion, 123 a sample of 71 was obtained, and the full list is in the additional files (see Additional file 4). 124 A subsample for the OECD was also built. Not all OECD members were included due to lack 125 of information or because they do not meet the abovementioned criterion for COVID-19

\footnotetext{
${ }^{5}$ https://github.com/owid/covid-19-data/find/master

${ }^{6}$ https://www.oecd.org/els/health-systems/health-data.htm

${ }^{7}$ https://www.who.int/healthinfo/en/
} 
126 deaths. For the panel data analysis, all available information was used, yet given that many

127 countries do not report daily ciphers, or they do not change over time, the sample is smaller,

128 reduced to 66. A full list of the countries used per model is presented in the additional files

129 (see Additional file 4).

130

131

132

133

134

135

136

137

138

139

140

141

142

143

144

145

\section{Ordinal Probit model specification}

An ordinal probit model allows the use of an ordinal list as a dependent variable, which can be numeric or categorical. The model was estimated with Stata. The dependent variable for this model is the CFR, which takes values from 1 to $N$, where 1 is assigned to the countries with the lowest CFR.

The estimation of CFR is difficult for several reasons. First, the universe of confirmed cases.

Due to the very different criteria for test applications, in most countries, the tests are administered only to those presenting symptoms, at least fever, or those requiring hospitalisation. Therefore, the universe of cases is well underestimated. Nonetheless, there is still no agreement over the likely size of this underestimation; depending on the study, the asymptomatic cases are estimated to be between 5\% and $80 \%$ (Heneghan, Brassey and Jefferson, 2020). For instance, Iceland is the country with more tests applied per million inhabitants due to a massive testing strategy. In this case, they identified $50 \%$ of the positive cases as asymptomatic (Heneghan, Brassey and Jefferson, 2020). In the case of the Diamond Princess cruise ship, the proportion of asymptomatic to total infected was estimated to be 17.9\% (Mizumoto, K., Kagaya, K., Zarebski, A., Chowel, G., 2020). Second, differences in registers. Some countries recognize COVID-19 death as suspicious; this is that lived with a former late COVID-19 patient or was closely related; meanwhile, other countries only account for the confirmed cases. Third, the timing matters. It has been confirmed that, similar 
150 to other viruses, once a person is infected, it takes up to two weeks to develop symptoms; if 151 that is the case, a person can develop a mild flu-like illness, which according to the first 152 Chinese analysis, this proportion was estimated to be up to $81 \%$ (Novel Coronavirus 153 Epidemiology Response, 2020). However, those entering severe and critical states might be 154 hospitalised, and it takes several days until a fatality occurs. In view of that, obtaining the 155 CFR by using the proportion of current deaths to current cases is a misleading indicator, since 156 the actual deaths from current cases will be reported later (Battegay et al., 2020).

157 Following the recommendation by Battegay et al. (2020), the third problem has been 158 addressed by estimating the CFR as follows:

$159 \quad$ CFR $_{i}=\frac{\text { Total deaths }_{i t}}{{\text { Total } \text { Cases }_{i, t-7}}_{1}}$ (1)

160 This measure is larger than a current indicator, yet it might be more accurate. Figure 2 shows 161 three different CFRs throughout the world. It is clear that the larger the lag in the total cases, 162 the larger the CFR will become. However, it is noticeable that they tend towards 163 convergence. 


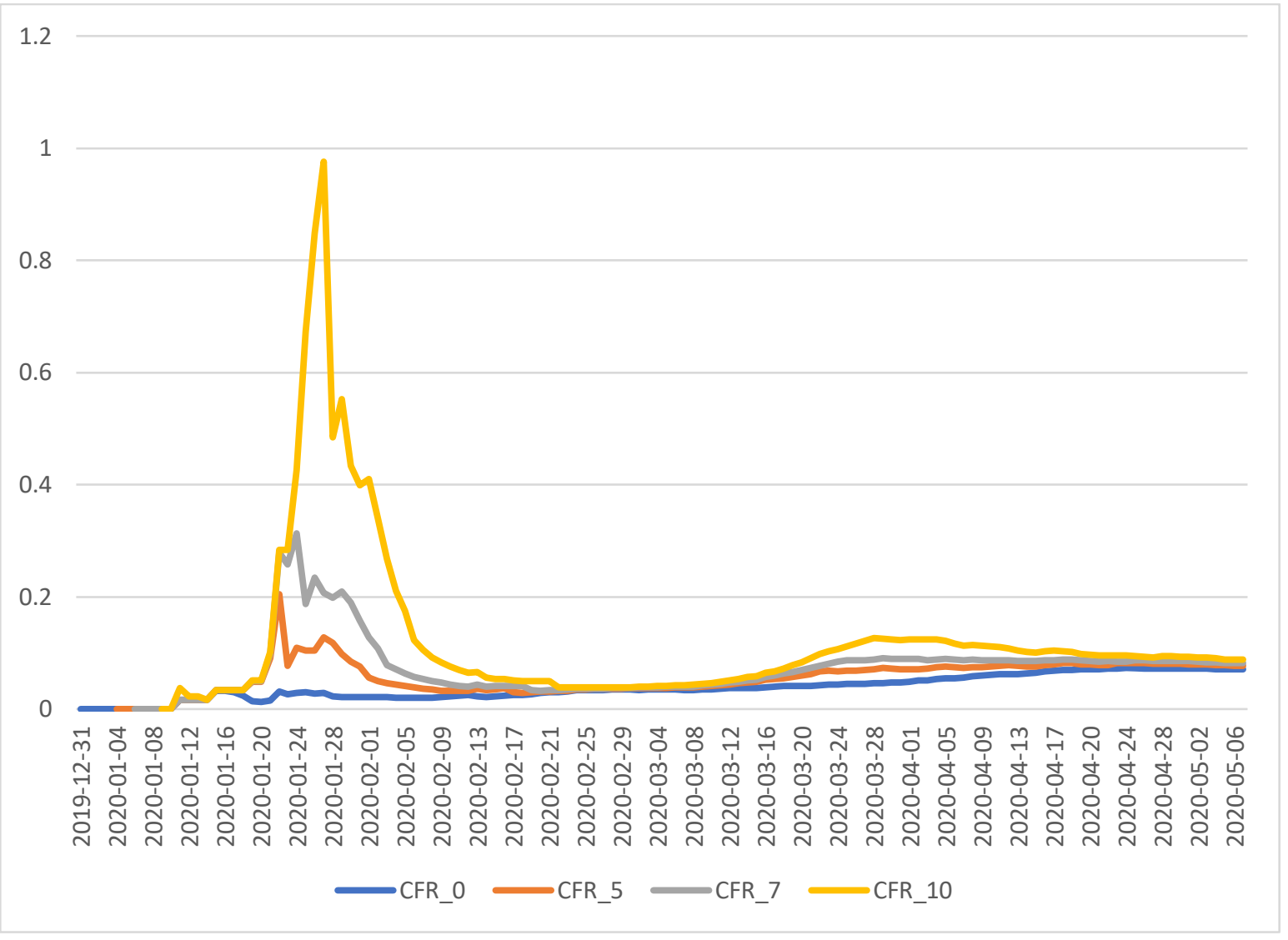

Figure 2 CFR for the world. Source: own elaboration.

In Table 1, the values at the beginning and end of the period are shown. For the three

167 indicators, the CFR is higher at the end of the period, and the difference among them 168 diminished.

Table 1 CFR for the Wold. Source: Own estimation with data from Oueworldindata.org

\begin{tabular}{|lrrrr|}
\hline Date & CFR_0 & \multicolumn{1}{c}{ CFR_5 } & CFR_7 & CFR_10 \\
\hline $2020-01-11$ & $1.7 \%$ & $1.7 \%$ & $1.7 \%$ & $3.7 \%$ \\
\hline $2020-05-07$ & $7.1 \%$ & $7.8 \%$ & $8.2 \%$ & $8.8 \%$ \\
\hline
\end{tabular}

171 It is also important to mention that the first reported death came on the $12^{\text {th }}$ day after the first 172 case was registered. Therefore, it is important to use a lagged number of cases for a better 173 estimate. 
174 The model used is as follows:

$175 \quad C F R_{i}=\beta_{i} X_{i}+\delta_{0}$ Testsmillion $+\varepsilon_{i}(2)$

176 where $C F R_{i}$ is the Case Fatality Rate ranking for country $i$; for the full CFR per country, see

177 the additional file (see Additional file 1), $X_{i}$ is a vector of variables corresponding to health

178 indicators, both on infrastructure and on population health, which could help to explain the

179 difference in CFR across countries, such as obesity, diabetes, presence of elderly people, and

180 others. It is important to mention that not all the variables are included at the same time in

181 the models to prevent biases, especially by the correlation among health expenditure,

182 infrastructure and population health indicators; the variables are not included in the model at 183 the same time.

184 The number of tests per million inhabitants is also included, since it has been claimed that 185 the only way to decrease the CFR in the long term is to massify the applied tests (OECD, 186 2020). Finally, considering that quarantine measures have been considered a determinant 187 factor for fatality rate, the Stringency index by Thomas et al. (2020) is also added as an 188 explanatory variable. This index is a wide indicator of all the different social measures taken 189 by governments to reduce the speed of spread, such as schools closing, cancelation of public 190 events, closing borders, etc. It is available daily for several countries. It gives a weight to 191 each measure taken, and the highest level for any given country is 100 .

192 Cross-section model specification.

193 These models are estimated by ordinary least squares (OLS) in Stata. The first model uses as 194 a dependent variable the total cases per million inhabitants, and the second model uses the 195 total of deaths per million inhabitants. The aim of this model is to show a robust statistical 
196

197

198

199

200

201 Finally, a group of panel data estimations have been made for evaluating greater robustness

202 for the models specified above. Panel data models can potentially include a larger number of

203 data by combining cross-section and time-series analysis. The cross-section models were

204 used to be able to link the dependent variables varying daily to annual variables by using one

205 static picture at the data. Instead, for the panel analysis, only data varying daily are used,

206 including cases, tests, deaths and the Stringency index. Given the type of data, these models

207 allow the use of dynamic variables. Thus, first differences of the dependent variables are

208 employed. Natural logarithms are used to find elasticities.

209 The models are specified as follows:

210

$\ln \left(\right.$ CFR $\left._{i t}-C F R_{i t-1}\right)=\alpha_{i}+\beta_{0}+\beta_{1} \operatorname{lnNewtestsmillion~}_{i t-7}+$

$211 \beta_{2}$ lnStringencyIndex ${ }_{i t}^{2}+\delta_{0}$ Time $_{t}+\varepsilon_{i t}(5)$

212

213

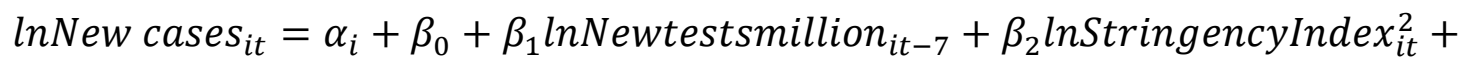

$\delta_{0}$ Time $_{t}+\varepsilon_{i t}(6)$

214 InNew deaths $_{i t}=\alpha_{i}+\beta_{1}$ lnNewtestsmillion $_{i t-7}+\beta_{2}$ lnStringencyIndex $_{i t}^{2}+$

$215 \delta_{0}$ Time $_{t}+\varepsilon_{i t}(7)$ 
216 For all the models, the explanatory variables are two: the $7^{\text {th }}$ lag of new tests per million

217 inhabitants and the square of the stringency index. The seventh lag of new tests per million

218 is used given the claims that early testing reduces the chances or greater infections (OECD,

219 2020). At the same time, similar to CFR, it is considered the time for the virus to develop;

220 for instance, a person who is asymptomatic today might develop symptoms within a week.

221 Mizumoto et al. (2020) estimated a range of 5.5 to 9.5 days for incubation, yet it is still

222 uncertain. There are cases in which people might show symptoms and die within a few

223 days $^{8}$. Given the difficulties determining the best lag to consider, two choices are shown,

224 the $7^{\text {th }}$ and the 15 th. Regarding quarantine measures, many countries converge to similar

225 levels in the index at the end of the period, yet squaring the variable allows us to model the

226 fact that the index has a maximum, and its marginal effect is smaller in the time.

227 Additionally, countries taking early measures should be able to content the spread to a

228 larger extent; thus, this is modelled through the initial larger marginal effect on the

229 dependent variables of a squared variable.

230 In equation 5, the model has as a dependent variable the natural logarithm of the first

231 difference in CFR. In equation 6, the dependent variable is the natural logarithm of new

232 COVID-19 cases per million (first difference of total COVID-19 cases per million) and, in

233 a similar fashion, the natural logarithm of new deaths per million (first difference of total

234 COVID-19 deaths per million). By using weighted variables per million inhabitants, the

235 population size differences across countries are addressed.

\footnotetext{
${ }^{8}$ Belgian girl becomes Europe's youngest coronavirus victim: media. Available at: https://www.reuters.com/article/us-health-coronavirus-belgium-death/belgian-girl-becomes-europesyoungest-coronavirus-victim-media-idUSKBN21I1W8
} 
236 All the variables and their summary statistics are shown in Table 2.

237 Table 2 Summary statistics. Source: Own elaboration

\begin{tabular}{lrrrr}
\hline & Mean & Maximum & Minimum & $\begin{array}{l}\text { Standard } \\
\text { Deviation }\end{array}$ \\
\hline CFR & \multicolumn{4}{c}{ Panel data } \\
\hline New cases per million & 0.0683694 & 9.5 & 0 & 0.1837786 \\
\hline New deaths per million & 12.49621 & 4944.376 & -139.488 & 66.70643 \\
\hline New tests per million & 0.5867564 & 200.04 & 0 & 3.860438 \\
\hline Stringency Index & 325.8418 & 7285 & 0 & 566.0734 \\
\hline & 32.84637 & 100 & 0 & 37.00693 \\
\hline CFR & & \multicolumn{4}{c}{ Cross-section } \\
\hline Total tests per million & 0.0633442 & 0.2009389 & 0.0084971 & 0.0438073 \\
\hline Health expenditure as GDP & 14153.18 & 80726.73 & 0 & 16803.75 \\
percentage (\%) & 6.869014 & 17.1 & 2.3 & 3.380769 \\
\hline Stringency Index & & & 0 & 20.52645 \\
\hline Total deaths per million & 79.54732 & 97.14 & 0.788 & 155.176 \\
\hline Total cases per million & 85.62903 & 719.523 & 34.875 & 1664.223
\end{tabular}

238

239 As seen in the last table, the mean CFR is similar for both datasets $(0.0683694$ and 240 0.0633442), which implies that the CFR keeps its trend in the time period analysed. Although

241 this is not the case for the coefficient of variation ${ }^{9}$, which is greater for the panel data (268.80)

242 than for the cross section (69.15), which is explained by the different results in the period for 243 the different countries.

244 It is also worth noting that the maximum CFR in the panel data can be higher than 1 . The 245 reason is that in countries with very explosive growth, the total cases confirmed one week 246 are less than the total deaths occurring the following week, by which time the confirmed 247 cases grew exponentially.

${ }^{9}$ (Standard Deviation / Mean)*100 


\section{Results}

249 In Table 3, the results for the ordinal probit model are presented. The infrastructure variables

250 and the population's health indicators were not statistically significant; instead, an indicator

251 for health expenditure was used. Since health expenditure is related to infrastructure 252 endowments and some population health indicators are related to expenditure, the variables

253 on infrastructure/population health and expenditure are alternatively used. Full tables with

254 all the considered variables are shown in the additional files (see Additional files 2 and 3 ).

255 Table 3 Estimation results from the ordinal probit model. Source: Own elaboration

\begin{tabular}{llllll}
\hline & & (1) & (2) & (3) & (4) \\
\hline Dependant Variable: CFR Ranking & Base line_71 & $\begin{array}{l}\text { Base } \\
\text { line_OECD }\end{array}$ & Stringency_71 & $\begin{array}{l}\text { Stringency_ } \\
\text { OECD }\end{array}$
\end{tabular}

\begin{tabular}{lllll}
\hline Total tests per million & $-0.00002^{* *}$ & $-0.00002^{*}$ & $-0.00002^{* *}$ & -0.00002 \\
\hline & $(0.00001)$ & $(0.00001)$ & $(0.00001)$ & $(0.00001)$ \\
\hline $\begin{array}{l}\text { Health expenditure as GDP } \\
\text { percentage }\end{array}$ & $0.1011467^{* * *}$ & 0.08313 & $0.09931^{* * *}$ & 0.08679 \\
\hline & & & & \\
\hline Stringency Index & $(0.03891)$ & $(0.06384)$ & $(0.03801)$ & $(0.06405)$ \\
\hline $\mathbf{N}$ & & 0.00404 & 0.00947 \\
\hline & \multicolumn{2}{c}{$(0.00600)$} & $(0.01095)$ \\
\hline & \multicolumn{2}{c}{31} & \multicolumn{2}{c}{71} \\
\hline
\end{tabular}

256 Columns 1 and 3 present the results for the sample with 70 countries, while columns 2 and 4

257 present those for the OECD members. A negative sign is shown between CFR ranking and

258 the total test per million; therefore, countries running more tests observed a larger probability

259 of having a lower CFR. In contrast, countries with larger expenditures on health observed a

260 larger probability of having a higher CFR. For the OECD subsample, only the first variable

261 was statistically significant. Finally, the stringency index is not statistically significant in any

262 case. 
In Table 4, the results from the cross-section model are displayed. In this model, only the

264 explanatory variables that were statistically significant in the previous model were used.

265 Columns 4 and 5 show that there is a positive correlation between the number of tests and

266 the total cases, which only confirms that the countries running more tests are identifying more

267 cases, yet this is not directly related to the number of deaths. In other words, the total tests

268 per million did not show a significant correlation with the number of fatalities.

269 Health expenditure is statistically significant for all the models. This is definitively related to 270 a problem of COVID-19 cases and deaths identification and records, rather than to causation.

271 This is, higher health expenditure as a GDP proportion cannot be a causal factor for larger

272 contagions and deaths related to COVID-19, but the positive correlation confirms that 273 countries spending more on health are identifying more cases and deaths. For instance, this 274 variable has a larger coefficient for OECD members, from which the majority are developed 275 countries and spend more on health as a GDP proportion. Namely, for OECD countries, the 276 average was $8.8 \%$, while for non-OECD countries, it was 5.32, while the difference in 277 purchasing power parity dollars is wider; on average, OECD countries spent \$2547 USD vs 278 \$1088 USD in non-OECD countries.

279 Table 4 Estimation results for cross-sectional models. Source: own elaboration.

\begin{tabular}{|c|c|c|c|c|}
\hline \multirow[t]{2}{*}{ Dependant Variable: } & \multicolumn{2}{|c|}{$\begin{array}{l}\text { Total cases per million } \\
\text { inhabitants }\end{array}$} & \multicolumn{2}{|c|}{$\begin{array}{l}\text { Total death per million } \\
\text { inhabitants }\end{array}$} \\
\hline & (5) & (6) & (7) & (8) \\
\hline & 71 & OECD & 71 & OECD \\
\hline \multirow[t]{2}{*}{ Total tests per million } & $0.03913^{* * *}$ & $0.05536^{* * *}$ & 0.00160 & 0.00162 \\
\hline & $(0.01074)$ & $(0.01237)$ & $(0.00100)$ & $(0.00181)$ \\
\hline Health expenditure as GDP percentage & $105.66169 * *$ & $171.89538^{* *}$ & $15.23655^{* * *}$ & $20.86109^{*}$ \\
\hline
\end{tabular}




\begin{tabular}{|c|c|c|c|c|}
\hline & $(52.48922)$ & (71.77250) & $(4.89474)$ & $(10.51117)$ \\
\hline \multirow[t]{2}{*}{ Stringency Index } & 2.04969 & $25.49470^{* *}$ & 0.36923 & 2.27619 \\
\hline & $(8.47057)$ & $(12.33977)$ & $(0.78990)$ & $(1.80717)$ \\
\hline \multirow[t]{2}{*}{ Constant } & -234.87260 & $-.0176 \mathrm{e}+03^{* *}$ & -78.83186 & -264.24963 \\
\hline & (776.83271) & $(1284.56380)$ & (72.44148) & $(188.12600)$ \\
\hline $\mathbf{N}$ & 71 & 31 & 71 & 31 \\
\hline \multirow[t]{2}{*}{$\mathbf{R 2}$} & 0.259 & 0.482 & 0.197 & 0.171 \\
\hline & \multicolumn{4}{|c|}{ Standard errors in parentheses, $* p<.1 ; * * p<.05 ; * * * p<.01$} \\
\hline
\end{tabular}

Finally, the results from the panel data analysis are shown in Table 5. Fixed effects were chosen over random effects using the Hausman test as the criterion. In column 9, new tests per thousand inhabitants show a negative correlation with first difference of CFR, which means that countries applying more tests per capita showed smaller differences on CFR across the period; that is, CFR observed a trend of reduction. Consequently, this supports that the widespread application of tests to reduce the fatality rate has been effective. In addition, it is also expected that CFR from countries identifying more positive cases converge to the real CFR, given that massive testing will give the true proportion between contagions and deaths. In the same model, the Stringency index coefficient is not statistically significant, and the trend is negative, as expected, since it should be smaller over time. It is important to note that the panel data are unbalanced, and all countries with available data are included, which are mostly from Europe, Asia, North America and South America.

In columns 10 and 11, the dependent variables showed a high positive correlation with new tests, similar to the previous models. This means that the correlation between testing the new deaths and new cases is sustained over time. Meanwhile, the stringency index showed

297 a negative coefficient; nonetheless, it is only statistically significant in column 11, with new deaths as the dependent variable. Therefore, it is confirmed that stringency measures have 
299 helped to reduce the number of COVID-19 deaths, but there is no statistical evidence of

300 being effective in reducing the number of new cases. The trend means that new deaths have

301 a significantly positive trend, meaning that they are still growing.

302 Table 5 Panel data estimation results. Source. Own estimation

\begin{tabular}{|c|c|c|c|c|c|c|}
\hline & (9) & (10) & (11) & (12) & (13) & (14) \\
\hline $\begin{array}{l}\text { Dependent } \\
\text { Variable: }\end{array}$ & Ln CFR ${ }_{0}-C R_{-1}$ & $\begin{array}{l}\text { Ln New } \\
\text { cases per } \\
\text { million }\end{array}$ & $\begin{array}{l}\text { Ln New } \\
\text { deaths per } \\
\text { million }\end{array}$ & $\mathrm{Ln} \mathrm{CFR}_{0^{-}} \mathrm{CFR}_{-1}$ & $\begin{array}{l}\text { Ln New } \\
\text { cases per } \\
\text { million }\end{array}$ & $\begin{array}{l}\text { Ln New } \\
\text { deaths per } \\
\text { million }\end{array}$ \\
\hline \multirow[t]{2}{*}{$\begin{array}{l}\text { Ln Stringency } \\
\text { index }{ }^{2}\end{array}$} & 0.0623 & -0.0287 & $-0.0671 * *$ & 0.0502 & -0.0240 & $-0.0643 * *$ \\
\hline & (0.0590) & $(0.0274)$ & $(0.0266)$ & $(0.0653)$ & $(0.0287)$ & $(0.0251)$ \\
\hline \multirow[t]{2}{*}{ Time } & $-0.0571 * * *$ & $-0.0171^{* *}$ & $0.0270 * * *$ & $-0.0585^{* * *}$ & $-0.0209 * *$ & $0.0149 *$ \\
\hline & $(0.0131)$ & $(0.0070)$ & $(0.0074)$ & $(0.0168)$ & $(0.0092)$ & $(0.0081)$ \\
\hline \multirow[t]{2}{*}{$\begin{array}{l}\text { Ln New tests } \\
\text { per million } \\
\text { inhabitants } \mathrm{t}-7\end{array}$} & $-0.8063^{* * *}$ & $0.6508 * * *$ & $0.4765^{* * *}$ & & & \\
\hline & $(0.1827)$ & $(0.0746)$ & $(0.0907)$ & & & \\
\hline \multirow[t]{2}{*}{$\begin{array}{l}\text { Ln New tests per } \\
\text { million } \\
\text { inhabitants }_{\mathrm{t}-15}\end{array}$} & & & & $-0.6123^{* * *}$ & $0.3515 * * *$ & $0.3644 * * *$ \\
\hline & & & & $(0.1919)$ & $(0.0836)$ & $(0.0906)$ \\
\hline \multirow[t]{2}{*}{ Constant } & $\begin{array}{c}1253.6235^{* *} \\
*\end{array}$ & $\begin{array}{c}376.2262 * \\
*\end{array}$ & $\begin{array}{c}- \\
597.7731^{* *} \\
*\end{array}$ & $\begin{array}{l}1282.9684^{* *} \\
*\end{array}$ & $\begin{array}{l}459.9860 * \\
*\end{array}$ & $\begin{array}{l}- \\
329.5989 *\end{array}$ \\
\hline & -287.5767 & -153.4644 & -162.1304 & $(368.6225)$ & $(202.0653)$ & $\begin{array}{l}\text { (179.0541 } \\
\text { ) }\end{array}$ \\
\hline Observations & 109 & 316 & 190 & 92 & 243 & 160 \\
\hline $\mathbf{N}$ & 48 & 64 & 53 & 42 & 59 & 49 \\
\hline R2 & 0.689 & 0.381 & 0.541 & 0.641 & 0.124 & 0.392 \\
\hline
\end{tabular}

304 As a robustness check, a longer lag has been included, which is the $15^{\text {th }}$ lag of new tests per 305 million, to control if there is any change over time. The results are very consistent, the 306 variables kept the same sign, and they remained statistically significant. The value of $\mathrm{R}^{2}$ 307 diminished for the three models, which can be affected by the smaller number of observations 308 and countries included. 
311 Our results support the WHO recommendations to increase testing and track of COVID-19

\section{Discussion} cases in all countries, given its definitive impact on reducing the CFR. In line with Stojkoski et al. (2020), we found that the countries' expenditure on health as well as their development level is positively related to CFR, cases and deaths, which cannot be interpreted as causation, but it indicates that developing countries do not track enough cases yet. Consequently, we claimed that there is an underidentification of data given the positive correlation between cases and deaths and testing, meaning that testing is still reactive and with little identification of asymptomatic, which is also highlighted by the OECD (2020) and the WHO (2020). Furthermore, given the under identification of cases, it is still very difficult to identify the country-specific drivers for contagions and CFR.

Lockdown measures, by the Stringency index, were shown to be effective at reducing the number of new deaths, yet it was not for new cases and CFR. Therefore, the results support the propositions to stop severe lockdown measures given the heavy economic losses and burdens for governments, which in turn will not significantly reduce the number of cases and CFR.

One significant limitation of this study is the usage of aggregated national data, rather than regional data, which could have helped to identify regional socioeconomic drivers for the COVID-19 spread and CFR, given that in some countries, the cases seemed to be very concentrated within few cities or regions. 


\section{Conclusions}

331 Testing proved to be a significant factor in decreasing CFR; thus, it should be supported as

332 the main strategy to follow for pandemic control in the medium and long terms. The findings 333 suggest that there is a large underidentification of COVID-19 cases, especially for developing 334 countries, which compromises the long-term control of the pandemic. Thus, it is essential to 335 make agreements with all nations to keep increasing the testing for further knowledge of the 336 COVID-19 and its spreading drivers at the national level, allowing tailored public policies.

337 The data show a particular performance for the cross-section, in which the coefficient of 338 variation is very low, but this trend changes when using panel data, in which the coefficient 339 of variation shows a significant change. In this case, the panel data regression analysis 340 captures the idiosyncratic errors in this time period, with a more precise estimation of the 341 effects of the test per million habitants.

342 By means of using the Stringency Index, it was found that lockdown measures have been 343 effective in reducing the number of new deaths, while they showed no impact on new cases 344 and CFR reduction. This has public policy implications, since lockdown measures generate 345 great economic losses and are already inducing economic crises all over the world, with 346 greater affectations for developing and less developed countries (Loayza, 2020).

347 Another general conclusion is that the availability of data for all countries is still very limited, 348 which hinders further analysis of COVID-19 spread and CFR drivers at the national level. 349 This is, the question remained unanswered whether countries with large proportions of the 350 population aged over 65 or over 80 , such as Japan or Italy, are more susceptible to greater 351 CFR. Additionally, at the aggregate level, it was not possible to link variables such as obesity 352 and diabetes with a higher CFR or number of deaths. Likewise, there is a significant 
difference in infrastructure endowments across the sample used; nevertheless, the CFR or the

354 number of deaths appeared to be statistically explained by these factors.

355 The pandemic is still developing, and there are countries in which the highest peak of

356 contagions has not yet been reached; thus, further analysis for narrowed public policies will

357 be needed. The current recommendation from the WHO, OECD, and other medical bodies

358 to increase testing proved to be the wiser path to follow at the moment.

359 List of abbreviations

360 CFR Case Fatality Rate

361 OECD Organisation for Economic Cooperation and Development

362 WHO World Health Organization

363 WLO World Labour Organization

\section{References}

366 Battegay Manuel et al., 2019-Novel Coronavirus (2019-nCoV): estimating the case fatality

367 rate - a word of caution. Swiss Med Wkly.n2020;

368 DOI: https://doi.org/10.4414/smw.2020.20203

369 CDC (Center for Desease Control and Prevention).Serology testing for COVID-19. 2020..

370 Available at: https://www.cdc.gov/coronavirus/2019-ncov/lab/serology-testing.html

371 Accessed on $15^{\text {th }}$ May 2020

372 Thomas, H., Angrist, N., Kira, B., Petherick, A., Phillips, T., Webster, S. Variation in

373 Government Responses to COVID-19. Version 5.0. Blavatnik School of Government

374 Working Paper. April 29, 2020. Available: www.bsg.ox.ac.uk/covidtracker

375 Heneghan, C., Brassey, J., and Jefferson, T. COVID-19: What proportion are asymptomatic?

376 2020. Available at: https://www.who.int/healthinfo/en/

377 Owid/Covid-19 data: https://github.com/owid/covid-19-data/find/master, last visited $19^{\text {th }}$ 378 May 2020. 
407

408 corresponding author on reasonable request.

Loayza, N. Smart containment and mitigation measures to confront the COVID-19 pandemic: Tailoring the pandemic response to the realities of developing countries. World Bank blogs. 2020. Available at: https://blogs.worldbank.org/developmenttalk/smartcontainment-and-mitigation-measures-confront-covid-19-pandemic-tailoring. Accessed on $15^{\text {th }}$ May 2020.

Mizumoto, K., Kagaya, K., Zarebski, A., Chowell, G. Estimating the asymptomatic proportion of coronavirus disease 2019 (COVID-19) cases on board the Diamond Princess cruise ship, Yokohama, Japan. Euro Surveill. 2020;25(10): pii=2000180. https://doi.org/10.2807/1560-7917.ES.2020.25.10.2000180

Sánchez, E. COVID-19 science: Why testing is so important. American Hart Association. 2020. Available at: https://www.heart.org/en/news/2020/04/02/covid-19-science-whytesting-is-so-important Accessed on $15^{\text {th }}$ May 2020

Stojkoski, V., Utkovski, Z., Jolakoski, P., Tevdovski, O., Kocarev, L., The socio-economic determinants of the coronavirus disease (COVID-19) pandemic. medRxiv preprint. 2020. doi: https://doi.org/10.1101/2020.04.15.20066068

The Novel Coronavirus Pneumonia Emergency Response Epidemiology Team. Vital Surveillances: The Epidemiological Characteristics of an Outbreak of 2019 Novel Coronavirus Diseases (COVID-19) — China, 2020.

World Health Organisation. Considerations in adjusting public health and social measures in the context of COVID-19.16 April. 2020 Available at: https://www.who.int/publicationsdetail/considerations-in-adjusting-public-health-and-social-measures-in-the-context-ofcovid-19-interim-guidance

\section{Declarations}

\section{Ethics approval and consent to participate}

Not Applicable

\section{Consent for publication}

Not Applicable

\section{Availability of data and materials}

07 The datasets used and/or analysed during the current study are available from the

\section{Competing interests}

10 The authors declare that they have no competing interests. 


\section{$411 \quad$ Funding}

412 Not Applicable

413 Authors' contributions

414 IA, C. Gathered most of the data, estimated the statistical models and is a major writer 415 contributor to the paper.

416 AO, A He helped with data collection and analysis of the results and is a minor writer

417 contributor of the document.

418 All authors read and approved the final manuscript.

$419 \quad-\quad$ Acknowledgements

420 Not Applicable

421 Authors' information (optional)

422 IA, C. She holds a PhD in Economics by the University of Glasgow. She currently works as 423 a lecturer at the School of Economics and Social Sciences at the Universidad Autonoma de 424 Sinaloa, Mexico. Additionally, she teaches at the Master in Public Administration at Unicaf

425 University. Her research interests are within regional economics, regional policies and 426 development, and local governments. 
Figures

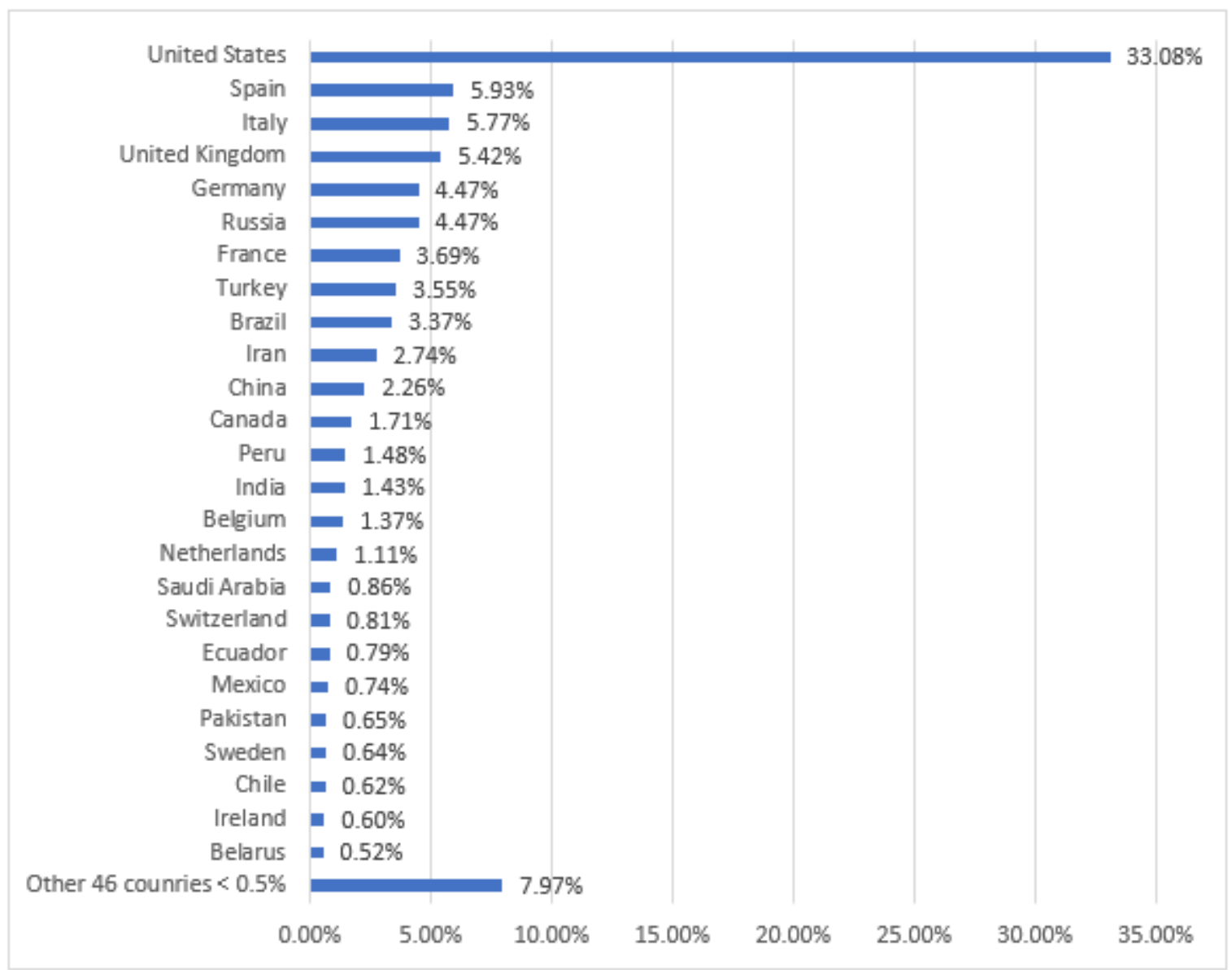

Figure 1

Proportion of cases by country by 7th May 2020. Source: own elaboration with data from Ourworldindata.org 


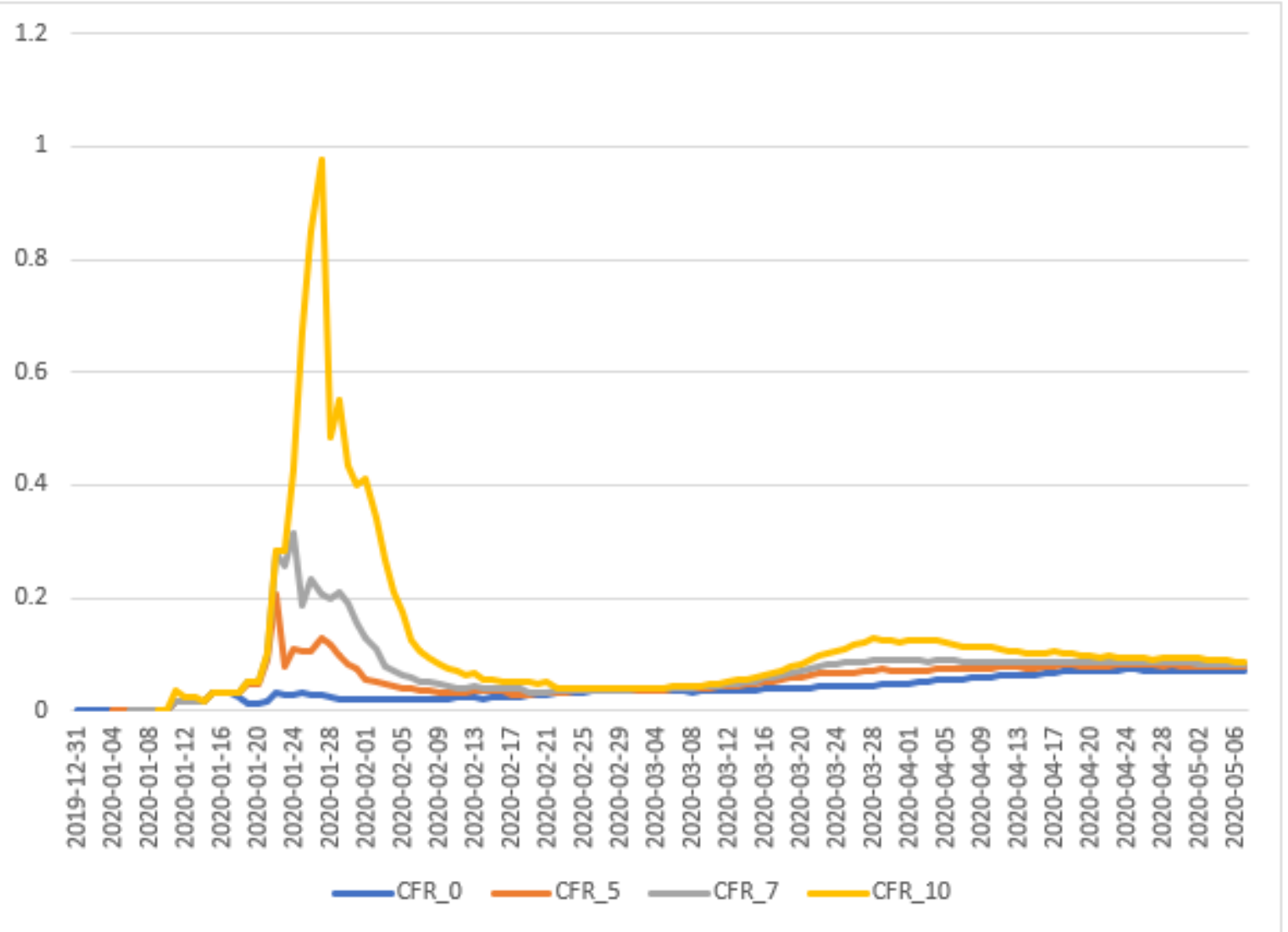

Figure 2

CFR for the world. Source: own elaboration.

\section{Supplementary Files}

This is a list of supplementary files associated with this preprint. Click to download.

- AdditionalTablesblind.docx 